\title{
STRATEGI BAURAN PEMASARAN DI AGROWISATA BUANA AMETHA SARI
}

\author{
Nami Fitricia Pasaribu \\ Hotel Management Department, Faculty of Economic and Communication, BINUS University \\ Jln. K.H. Syahdan No. 9, Palmerah, Jakarta Barat 11480 \\ nfitricia@binus.edu
}

\begin{abstract}
Object of this research is Agrowisata Buana Amertha Sari, Bali. Limitation on this study is marketing mix, especially on product and promotion. Coffee is the main comodity in Agrowisata Buana Amertha Sari, while promotion is conducted through words of mouth method and in cooperation with local guides. Agrowisata Buana Amertha Sari uses website to promote its products. Within this research, it is expected the use of social media Facebook and Twitter could make contribution in boosting the recognition to global customers. This research is qualitative using interview and observation at one time in May 2013.
\end{abstract}

Keywords: agrotourism, marketing mix, promotion, products

\begin{abstract}
ABSTRAK
Penelitian mengambil objek Agrowisata Buana Amertha Sari, Bali. Batasan penelitian adalah bauran pemasaran, yaitu produk dan promosi. Produk utama Agrowisata Buana Amertha Sari adalah kopi; sedangkan promosi yang dilakukan menggunakan metode words of mouth serta bekerja sama dengan pramuwisata lokal. Sarana website menjadi alat promosi yang dilakukan, diharapkan dengan menggunakan media sosial seperti Facebook dan Twitter dapat membantu pengenalan Agrowisata Buana Amertha Sari kepada pelanggan global. Penelitian ini adalah penelitian kualitatif, yang menggunakan teknik wawancara dan observasi langsung pada satu waktu di bulan Mei 2013.
\end{abstract}

Kata kunci: agrowisata, bauran pemasaran, promosi, produk 


\section{PENDAHULUAN}

Indonesia adalah negara nomor tiga penghasil kopi dunia. Hal ini memberikan pandangan bahwa banyak sekali perkebunan kopi di seluruh Indonesia. Ditunjang dengan iklim tropis dan berada pada garis khatulistiwa, Indonesia memiliki tingkat kesuburan tanah yang baik untuk perkebunan. Pada 1800 Indonesia telah menghasilkan komoditas pertanian dan perkebunan ke negara-negara Eropa seperti cengkih, pala, kokoa, teh, kopi, dan gula. Tiga dekade lalu perekonomian di Bali disokong oleh pertanian dan perkebunan. Komoditas yang dihasilkan di antaranya adalah padi, buah, sayur, dan kopi arabika. Penghasil terbesar kopi arabika terdapat di daerah tinggi yaitu Kintamani, dekat dengan pegunungan Batur. Kintamani adalah kecamatan di kabupaten Bangli. Untuk mendapatkan biji kopi, petani kopi di Bali menggunakan metode wet process method (menggunakan air yang cukup banyak), dan sistem pengairan yang terkenal di Bali disebut Subak Abian. Kopi arabika Kintamani merupakan produk pertama dari Indonesia yang mengajukan permohonan Indikasi Geografis (Geographical Indication). Indikasi Geografis adalah nama atau tanda yang digunakan pada produk-produk khusus yang secara spesifik menyatakan lokasi geografi dan asal produk. Penggunaan dari Indikasi Geografis tersebut akan melalui sertifikasi yang menyatakan kepemilikan produk dan kualitas khas. Indikasi Geografis membantu pengenalan daerah penghasil produk yang telah disertifikasi. Hal ini merupakan sarana promosi yang baik bagi daerah atau suatu tempat. Di Bali, pada 2004, agrowisata mulai dikembangkan serius dan dijadikan daya tarik wisata. Daerah yang menjadi pusat agrowisata adalah kecamatan Bangli. Dengan ketinggian dari permukaan laut sekitar 1000-1500 wilayah ini saat baik bagi perkebunan. Selain kopi, Bangli juga menghasilkan hasil kebun seperti kopi (varietal arabika), vanila, jeruk (citroen), kokoa, kayu manis, dan salak (snake skin fruit). Buana Amertha Sari berlokasi di daerah pegunungan di Kecamatan Bangli, Kintamani, Bali. Berada di ketinggian 1000 dpl, area ini memberikan suasana yang baik untuk tumbuhnya tanaman kopi. Budidaya kopi luwak di tempat ini menjadi daya tarik tersendiri bagi wisatawan.

Pada penelitian ini, Agrowisata Buana Ametha Sari adalah objek wisata kebun yang menarik untuk diteliti. Produk yang dihasilkan dari tempat ini merupakan hasil bumi Bali setempat antara lain kokoa, kopi, vanila, kayu manis, dan minyak esensial natural. Selain itu Agrowisata Buana Amertha Sari juga memberikan nilai tambah dengan membuat inside store dan atribut augmentasi lainnya. Promosi yang dilakukan oleh Agrowisata Buana Amertha Sari adalah dengan metode words of mouth yang mengandalkan para pramuwisata lokal dan dengan membuat website yaitu www.balinature.com. Namun demikian, belum ada sarana promosi dengan menggunakan media sosial facebook ataupun twitter guna menunjang pengenalan tempat kepada konsumen secara luas. Swarbrooke (2002) menyatakan bahwa motivasi terbesar untuk melakukan ekowisata adalah keinginan untuk melihat ekosistem yang terdapat pada alam atau lingkungan hidup sekitar, dalam hal ini kehidupan liar dan populasi asli. Lalu berkembang pendapat akan ekowisata, dengan adanya keinginan wisatawan untuk juga menyaksikan pelestarian ekosistem asli dan kehidupan yang dijalani populasi asli. Secara umum daerah dataran tinggi memiliki populasi yang jarang. Meskipun terdapat komunitas yang menaungi dan perlu dipertimbangkan, komunitas ini memiliki mata pencaharian dari bertani dan agrikultura, memiliki kecenderungan kehilangan generasi muda yang akan meneruskan tradisi yang ada, memiliki sistem poltik komunitas dan tata cara pemerintahan etnis yang tiak disokong penuh oleh pemerintah secara luas.

Penelitian ini mengidentifikasi bauran pemasaran yang dilakukan di Buana Amertha Sari. Kemudian memberikan gagasan untuk melakukan promosi secara digital dengan membuat akun twitter dan facebook. Promosi digital diperlukan untuk memperkenalkan Buana Amertha Sari kepada publik secara luas dan menjual produk secara online. 


\section{Kajian Teori}

Sebelum lebih jauh mengenal analisis pemasaran, ada baiknya mengenal lebih dulu definisi pemasaran. Menurut Kotler (2012):

"Tujuan pemasaran adalah membuat penjualan tidak diperlukan lagi. Penjualan dan iklan hanyalah bagian dari bauran pemasaran (marketing mix) yang lebih besar -seperangkat sarana yang bekerja sama untuk memuaskan kebutuhan pelanggan dan menciptakan hubungan dengan pelanggan."

Kotler (2012) mengemukakan bahwa pemasaran adalah proses penciptaan nilai oleh perusahaan kepada pelanggan, serta membangun hubungan yang kuat dengan pelanggan yang bertujuan mengambil nilai dari pelanggan sebagai hasilnya. Lovelock (2010) mengemukakan bahwa dalam pemasaran terdapat bauran pemasaran yang dikenal dengan 4P yaitu Product (produk), Price (harga), Place (distribusi atau tempat), dan Promotion (promosi). Namun dalam bidang jasa dikembangkan menjadi 8P. Terjadinya pengembangan ini disebabkan uniknya transaksi yang dilakukan dalam bidang jasa. Dalam transaksi jasa ada faktor keterlibatan pelanggan dalam produksi, serta faktor waktu (timing) sangatlah penting. Berikut dijabarkan 8P tersebut.

Pertama, product (produk), adalah produk inti yang diberikan oleh perusahaan baik barang maupun jasa (core products) berikut juga produk jasa pelengkap (augmented product) yang dapat memberikan keselarasan untuk memenuhi kebutuhan pelanggan. Kedua, place and time (tempat dan waktu); dalam proses mengirimkan barang ataupun jasa dibutuhkan keputusan mengenai tempat dan waktu, dan melibatkan saluran distribusi fisik dan elektronik bahkan bisa jadi terdapat keduanya. Ketiga, process (proses); dalam proses terdapat penjelasan dari metode kerja dari sistem yang digunakan untuk operasional. Jika desain dari proses dibuat dengan baik dan bijak, akan dihasilkan penyampaian yang efektif kepada pelanggan. Keempat, productivity and quality (produktivitas dan kualitas); produktivitas yang baik adalah kinerja untuk menjaga biaya dalam kendali, namun dalam mengendalikan biaya tersebut jangan sampai mengorbankan kualitas yang baik. Keseimbangan dalam produktivitas dan kualitas akan membawa perusahaan untuk memiliki diferensiasi produk dan loyalitas pelanggan. Kelima, people (orang); transaksi yang terjadi dalam bidang jasa adalah interaksi langsung dari pelanggan dengan karyawan yang bekerja. Sehingga dalam perekrutan, pelatihan, dan pemberian motivasi seluruh karyawan yang bekerja menjadi landasan utama agar terjadi kepuasan kepada pelanggan. Keenam, promotion and education (promosi dan edukasi); program pemasaran yang berhasil adalah program komunikasi yang memberikan promosi dan pendidikan kepada pelanggan. Tiga lakon penting pada elemen ini adalah menyediakan informasi dan saran yang tepat guna, mempersuasi pelanggan sasaran tentang kelebihan suatu produk, dan membuat pelanggan mengambil tindakan dalam kurun waktu yang ditentukan. Ketujuh, physic (bukti fisik), disebut juga sebagai tangible product adalah sesuatu yang dapat dilihat dan dirasakan sebagai bukti atas kualitas jasa. Kedelapan, price and other cost (harga dan biaya jasa lainnya), merupakan alat bagi manajemen sebagai tolok ukur yang memperlihatkan macam-macam biaya yang dihasilkan oleh perusahaan untuk memberikan manfaat prouduk dan jasa kepada pelanggan.

\section{Manajemen Strategis}

Menurut David (2002), manajemen strategis adalah seni dan science dalam memformulasi, mengimplementasikan, dan mengevaluasi keputusan-keputusan lintas fungsional yang akan memungkinkan sebuah organisasi untuk meraih tujuan-tujuannya. Sembilan istilah kunci untuk manajemen strategis adalah keunggulan kompetitif (competitive advantage), pelaku strategi (strategists), visi dan misi (vision and mission statements), peluang dan ancaman dari luar (external opportuinities and threats), kekuatan dan kelemahan dari dalam (internal strength and weaknesses), tujuan jangka panjang (long-term objectives), strategi-strategi terpilih (strategies), dan tujuan tahunan dan kebijakan (annual objectives and policies). Sementara Supranto (2011), mengemukakan bahwa 
strategi pemasaran merupakan perumusan bauran pemasaran yang konsisten guna memberikan kepuasan pada konsumen.

\section{METODE PENELITIAN}

Penelitian berawal dari keingintahuan akan program agrowisata di pulau Bali, tentang alasan Bali membuat suatu daerah khusus yang mengangkat agrowisata dalam pengembangan wisatanya. Studi ini dilakukan untuk menganalisis pemasaran Agrowisata Buana Amertha Sari, Bangli kecamatan Kintamani. Penelitian menganalisis bauran pemasaran jasa, yaitu 8P: produk (products), tempat dan waktu (time and place), proses (proccess), produktivitas dan kualitas (productivity and quality), orang (people), promosi dan edukasi (promotion and education), bukti fisik (physic) serta harga dan biaya lainnya (price). Lingkungan pemasaran terdiri dari lingkungan eksternal dan lingkungan internal. Menggali faktor lingkungan eksternal merupakan upaya untuk melihat faktor-faktor yang memengaruhi peluang dan yang menjadi ancaman bagi perusahaan. Hal ini dapat dilakukan dengan menganalisis lingkungan mikro dan lingkungan makro. Lingkungan mikro adalah pelanggan, pemasok, dan pesaing; sedangkan lingkungan makro adalah lingkungan politik, ekonomi, sosial budaya, dan teknologi. Selain lingkungan eksternal, diperlukan juga analisis terhadap lingkungan internal agar dapat mengidentifikasi kekuatan dan kelemahan yang dimiliki oleh perusahaan yang dikenal sebagai strength and weakness pada analisis SWOT. Langkah berikutnya adalah menentukan critical factors untuk kekuatan, kelemahan, peluang, dan ancaman Agrowisata Buana Amertha Sari lalu dirumuskan ke dalam matriks Internal matrix Evaluation (IFE) dan External Matriks Evaluation (EFE).

Setelah melakukan matrix IFE dan EFE, dilakukan proses pencocokan (matching) faktor internal dan eksternal untuk mencari strategi yang semakin detail dengan menggunakan SWOT analysis. Tahap akhir adalah mengambil keputusan dari hasil yang ditemukan dengan menggunakan QSPM (Quantitative Strategic Planning Matrix).

Teknik pengumpulan data pada penelitian ini dilaksanakan di Agrowisata Buana Amertha Sari pada bulan Mei tahun 2013 dengan melakukan indepth interview (semistructured and unstructured) kepada pemilik usaha dan pekerja untuk data matriks IE dan analisis SW. Kemudian kuesioner disebarkan kepada karyawan dan pemilik Agrowisata Buana Ametha Sari. Observasi partisipatif moderat dilakukan langsung ke Agrowisata Buana Amertha Sari untuk melihat lokasi dan pengambilan dokumentasi. Menurut model Miles and Huberman dalam Sugiyono (2012), analisis data di lapangan dilakukan pada saat penelitian berlangsung dan setelah penelitian dilaksanakan, dan dilakukan antisipasi data serta kemudian dilakukan reduksi data untuk menyajikan dalam pola dan verifikasi data. Penelitian ini menggunakan literatur lokal dan luar negeri untuk mengakomodasi informasi. Sumbernya berasal dari perpustakaan, buku ilmiah, jurnal, data lembaga pemerintahan terkait (perkebunan dan pariwisata) dan sumber elektronik sebagai pengayaan informasi terkini.

Unit analisis untuk data primer pada penelitian dijelaskan pada Tabel 1.

Tabel 1 Tabel Unit Analisis data Primer dan Teknik Pengumpulan Data

\begin{tabular}{clll}
\hline JENIS & \multicolumn{1}{c}{ SUMBER DATA } & TEKNIK PENGUMPULAN & \multicolumn{1}{c}{ KETERANGAN } \\
DATA & & \multicolumn{1}{c}{ DATA } & \\
\hline Primer & Pemilik dan Karyawan & In depth Interview & Unstructured and structured Interview \\
& Konsumen ahli & Interview & Unstructured and structured Interview \\
& Pelaku bisnis & Interview & Unstructured and structured Interview \\
& Akademisi & Interview & Unstructured and structured Interview \\
& Pemerintah Daerah & Interview & Unstructured and structured Interview \\
\hline
\end{tabular}


Data primer dalam penelitian diambil dari pemilik dan karyawan Agrowisata Buana Amertha Sari, untuk mengambil data bauran pemasaran yang dilakukan di Agrowisata Buana Amertha Sari. Konsumen ahli dalam penelitian ini adalah para pemerhati agrowisata dan penikmat produk hasil agrowisata. Akademisi adalah pemberi masukan terhadap perkembangan pemasaran yang dapat dilakukan Agrowisata Buana Amertha Sari. Pemerintah daerah merupakan instansi yang memberikan kebijakan yang akan memperngaruhi keputusan yang diambil oleh perusahaan, sehingga perlu dilakukan wawancara untuk menganalisa sejauh mana pengembangan penelitian ini dapat dilakukan untuk Agrowisata Buana Amertha Sari.

\section{HASIL DAN PEMBAHASAN}

Hasil dalam penelitian ini adalah pemilik dan karyawan belum terlalu mementingkan sosial media dalam satu sampai dua tahun ke depan. Namun demikian, pemilik agrowisata ingin mengembangkan media promosi melalui website. Penjualan produk tidak ingin dilakukan secara online karena pemilik ingin menjadikan pengalaman kunjungan langsung ke lokasi Agrowisata Buana Amertha Sari menjadi produk yang utama. Gambar 1 merupakan pintu masuk Agrowisata Buana Amertha Sari, setelah melewati kebun dan toko tempat menjual produk hasil kebun. Pada sisi kanan jalan merupakan dapur membuat minuman tester bagi para tamu yang berkunjung dan disajikan gratis; pada sisi kiri merupakan tempat beristirahat pada tamu.

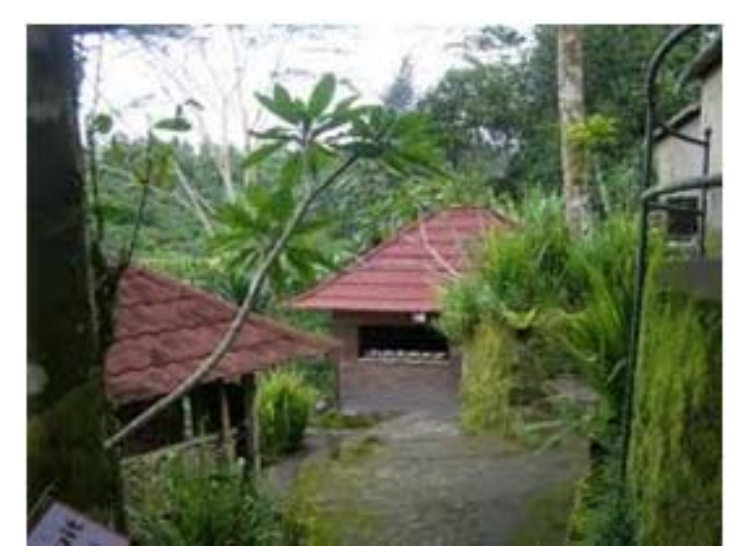

Gambar 1 Pintu Masuk Agrowisata Buana Amertha Sari

Agrowisata Buana Amertha Sari dapat bekerja sama dengan pemerintah daerah untuk bisa dipromosikan ke dalam website pemerintahan, sehingga pemerintah berperan aktif untuk pengenalan destinasi agrowisata di wilayah setempat.

Gambar 2 merupakan proses pemasakan kopi untuk seluruh produk kopi yang dijual di Agrowisata Buana Amertha Sari. Proses pemasakan kopi di Agrowisata Buana Amertha Sari menggunakan cara tradisional yang menggunakan tungku api dari kayu. Pengembangan produk kopi di Agrowisata Buana Amertha Sari disarankan untuk mengembangkan produk kopi campuran seperti kopi dengan cengkih, kopi dengan vanila, dan kopi rempah Bali. 


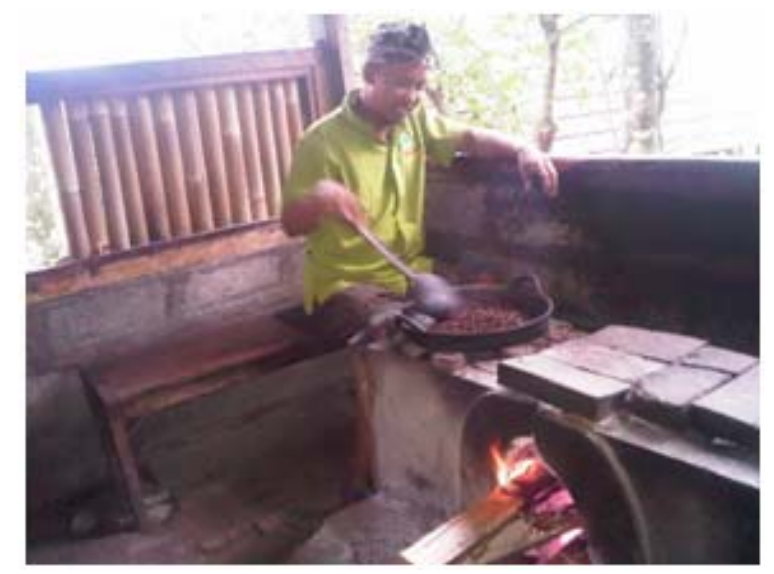

Gambar 2 Proses Memasak Kopi secara Tradisional

Saat ini kopi luwak menjadi komoditi utama di Agrowisata Buana Amertha Sari. Gambar 3 menunjukkan penyajian kopi luwak di Agrowisata Buana Amertha Sari dengan menggunakan alat seduh dari Jepang yaity Syphon. Alat ini merupakan metode manual tanpa mesin. Yang dibutuhkan adalah tungku api untuk memanaskan air menjadi uap.

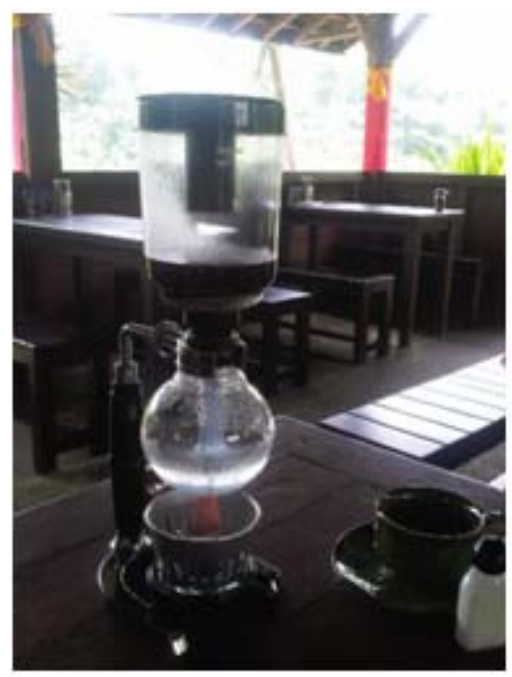

Gambar 3 Penyajian Kopi Luwak

Konsumen ahli menyatakan bahwa kopi luwak akan mengalami penyurutan minat pada 2014. Sehingga untuk mewaspadai hal tersebut, pengembangan produk sebaiknya dilakukan untuk menjaga variasi produk kopi.

\section{SIMPULAN}

Buana Amertha Sari merupakan suatu contoh riil pemasaran sederhana masih dapat dilakukan untuk sebuah perusahaan menengah. Namun dengan berkembangnya teknologi, ada baiknya Buana Amertha Sari mulai menerapkan pemasaran global untuk keberlanjutan usahanya. Penelitian ini memiliki batasan pada bauran pemasaran promosi dan produk. Untuk penelitian selanjutnya, dianjurkan membuat penelitian untuk strategi pemasaran dan analisis segmentasi pasar. 


\section{DAFTAR PUSTAKA}

David, R. F. (2011). Strategic Management. New Jersey: Pearson.

Kotler, P., and Armstrong, G. (2011). Prinsip-Pronsip Pemasaran. Jakarta: Erlangga.

Lovelock, C. H., and Wright, D. L. (2007). Manajemen Pemasaran Jasa. Jakarta: Indeks.

Sugiyono. (2012). Metode Penelitian Kuantitatif, Kualitatif dan R\&D. Bandung: Alfabeta.

Swarbrooke, J. (2002). Sustainable Tourism Management. CABI. 